\title{
Field study of energy performance of wood-burning stoves
}

\author{
Ole M. Jensen ${ }^{1 *}$, Alireza Afshari ${ }^{1}$, Niels C. Bergsøe ${ }^{1}$, Ricardo L. Carvalho ${ }^{1}$ \\ ${ }^{1}$ Danish Building Research Institute, Aalborg University, Hoersholm, Denmark \\ *Corresponding author. Tel: +45 99402373, Fax: +45 45867535, E-mail: omj@sbi.dk
}

\begin{abstract}
In Europe, large amounts of renewable energy are lost when residential buildings are heated by means of wood-burning stoves. Still, too many wood-burning stoves are energy inefficient, the knowledge of their operation is insufficient and the interaction between the stove and the house to be heated is not adequate. This applies in particular to old wood-burning stoves in old houses. However, this field study, the first ever dealing with new stoves in new houses, revealed that even in new houses with new wood-burning stoves of today the interplay between stove and house can still be improved as well as the modern wood-burning stoves could be designed to perform even better. However, calculation of heat balances and measurement of temperature in a series of single family houses showed that wood-burning stoves actually contribute considerably to the heating of new houses, although their intermittent working led to overheating and conflicts with the primary heating system. Moreover, measurements of particles showed that emission of fine and ultrafine particles to the indoor climate can easily occur.

The study made it clear that information and guidelines to be disseminated among stove manufactures, salesmen, and home owners are needed regarding dimensioning, installation of wood-burning stoves and their lighting and operation as well.
\end{abstract}

Keywords: Residential heating, wood-burning stoves, energy performance, particle emission, ultrafine particles

Although wood-burning stoves are mostly used as a supplementary heating source, they represent a notable part of the carbon-free heating. In Denmark, which has a well-developed gas and district-heating net, the share of wood is estimated to be $18 \%$ of the total amount of fuel used for heating in single-family houses, and amounts to $60 \%$ of the renewable energy contribution in these houses [1]. The large share of wood, mainly consumed in wood-burning stoves, can be ascribed to the fact that firewood is cheaper than other fuels and that Danish wood-burning stoves are popular due to their high efficiency, their certificates of low particle emission [2] and their design - not to forget their ability to create a cosy atmosphere. Therefore, when developing new models, the manufacturers have in turn focused on efficiency, environment and design. The focus on these elements has made it possible to meet the demands of a wide customer segment, including owners of new single-family houses with low energy demand.

So far, new single-family houses continue to have a decreasing demand of energy for heating. This is encouraged by the European Directive on the Energy Performance of Buildings (EPBD), which led to national legislation on better energy performance, i.e. better insulation and airtight building envelopes combined with ventilation systems with heat exchanger [3]. On this background, the aim of the field study was to:

- Investigate the energy performance of stoves in operation, the overall efficiency and utilisation of firewood.

- Determine the impact of wood-burning stoves used on the indoor environment in terms of particle pollution and thermal comfort.

- Give recommendations, guidance to manufacturers and users of wood-burning stoves.

\section{Study design}

A study design was chosen where seven residential buildings were selected for case studies. The criteria for selecting the houses were that they were built after 1995, i.e. within the period 
covered by the last two editions of the Danish Building Regulations and that they were equipped with a certified wood-burning stove. However, one house built in 1977 was included the study, because it was equipped with a masonry stove and because one elderly house would probably clarify the study.

A total of seven families with single-family houses hosted the surveys. The specifications concerning the selected houses are shown in Table 1 . The experimental hosts were identified by addressing stove manufacturers and suppliers. This resulted in five cast-iron stoves, certified according to Danish Standard, four of which were certified according to the Nordic Swan standard [4]. Two masonry stoves built on location were not certified. Instead similar masonry stoves were known for their quality and tested for their high energy efficiency.

Table 1. Hosts for the field study with type of house and type of stove listed with certification of house and stove included. Building energy class A refers to the most energy efficient buildings. DS (Danish Standard) + Swan (Nordic eco-label) refers to certified clean and energy efficient wood-burning stoves.

\begin{tabular}{lccccc}
\hline Hosts & $\begin{array}{c}\text { Type of } \\
\text { house }\end{array}$ & $\begin{array}{c}\text { Building } \\
\text { year }\end{array}$ & Energy class & $\begin{array}{c}\text { Type of } \\
\text { stove }\end{array}$ & Certification \\
\hline Espergaerde & detached & 1977 & $\mathrm{D}$ & masonry & (Solbyg) \\
Ringsted & detached & 2006 & $\mathrm{~B}$ & masonry & (Helbro) \\
Hilleroed & detached & 2001 & $\mathrm{C}$ & cast iron & DS + Swan \\
Virum & detached & 2007 & $\mathrm{~B}$ & cast iron & DS Plus \\
Værloese & row house & 2008 & $\mathrm{~B}$ & cast iron & DS + Swan \\
Esrum I & detached & 2009 & A2 & cast iron & DS + Swan \\
Esrum II & detached & 2009 & A2 & cast iron & DS + Swan \\
\hline
\end{tabular}

\section{Measurements}

The experimental hosts were visited in the heating seasons 2008/2009 and 2009/2010 respectively. The houses in Ringsted and Virum were not included in the first series of measurements. In turn, Esrum II was not included in the second series of the field study. In the first series, particles, gases and air-change rates were measured, before, during and after lighting. In these cases, the host lighted the fire in the stoves. In the second series also particles, gases and air-change rates were measured. This time also the temperature close to and at some distance from the stoves were measured. To ensure uniform lighting, a stoking expert was engaged to perform the lighting in the second series. In addition, programmable data loggers (TinyTags) recorded temperature and humidity continuously for the following months.

Each of the hosts was interviewed and questionnaires were distributed. The interview was conducted in order to clarify the occupants' habits concerning their use of the stove, the family's experience with using the stove, techniques for lighting etc. The survey was aimed at quantifying technical issues, including consumption of firewood, the type of any primary heating, preferred room temperature and bathing habits, etc.

\section{Energy performance}

Energy performance has become the mantra of energy supply. Focus has been directed at electric appliances, cars and buildings, but also at the way we produce energy. This demand has reached the energy performance of wood-burning stoves as well. Their energy performance has bee increased and as a consequence the new wood-burning stoves have reached an 
efficiency rate of 75-80 \%. At this level, however, the energy performance of wood-burning stoves cannot be seen in isolation from the building that is supplied. Therefore, the first move was to chart the heat balance of the system. The second move was to detect instances of overheating

\subsection{Heat balances}

For each of the houses involved in the field study, a heat balance was drawn up. One side of this balance gave the total of all inputs of fuel converted to a net heat production (excluding conversion loss). The other side of the balance gave the annual heat loss adjusted for the actual indoor temperatures, and the domestic hot water consumption. The total was termed gross heat consumption (including hot water etc.)

On the production side of the balance, the conversion of wood was rather uncertain. First the volume of firewood, the type of stack and the type of wood, included moisture content, must be known to estimate the dry firewood mass. Next, the heating value of the wood and the efficiency of the stove were needed for the calculation. Finally the extra heat loss caused by the additional air change of the wood burning must be taken into consideration, see Table 2 .

Table 2. Firewood converted to heat production. The efficiency of the stoves is determined from test results field studies [5]. The calculation of the ventilation heat loss is based on the need of $11 \mathrm{~m}^{3}$ air to convert $1 \mathrm{~kg}$ of dry wood.

\begin{tabular}{lccccc}
\hline Host & $\begin{array}{c}\text { Firewood } \\
(\mathrm{kg})\end{array}$ & $\begin{array}{c}\text { Calorific val- } \\
\text { ue } \\
(\mathrm{kWh} / \mathrm{kg})\end{array}$ & $\begin{array}{c}\text { Efficiency } \\
(\%)\end{array}$ & $\begin{array}{c}\text { Ventilation } \\
\text { loss (MWh) }\end{array}$ & $\begin{array}{c}\text { Net heat con- } \\
\text { tribution } \\
(\mathrm{MWh})\end{array}$ \\
\hline Espergaerde & 2520 & $4 ., 1$ & 80 & 0.16 & 8.1 \\
Ringsted & 980 & 4.1 & 85 & 0.06 & 3.4 \\
Hilleroed & 1750 & 4.1 & 75 & 0.11 & 5.5 \\
Virum & 350 & 4.1 & 70 & 0.02 & 1.1 \\
Værloese & 350 & 4.1 & 75 & 0.02 & 1.1 \\
Esrum I & 875 & 4.1 & 75 & 0.06 & 2.7 \\
Esrum II & 1400 & 4.1 & 75 & 0.09 & 4.4 \\
\hline
\end{tabular}

Altogether the different fuels contributed to the net heat production of the houses as seen in Table 3.

Table 3. Merging the heat production of firewood with the heat production of other energy sources.

\begin{tabular}{lccccc}
\hline Host & $\begin{array}{c}\text { Firewood } \\
(\mathrm{MWh})\end{array}$ & $\begin{array}{c}\text { District } \\
\text { heating } \\
(\mathrm{MWh})\end{array}$ & $\begin{array}{c}\text { Natural gas } \\
(\mathrm{MWh})\end{array}$ & $\begin{array}{c}\text { Heat pump } \\
(\mathrm{MWh})\end{array}$ & $\begin{array}{c}\text { Net heat } \\
\text { production } \\
(\mathrm{MWh})\end{array}$ \\
\hline $\begin{array}{l}\text { Espergaerde } \\
\text { Ringsted }\end{array}$ & 8.1 & & 31.7 & & 39.8 \\
Hilleroed & 3.4 & 7.8 & & & 11.2 \\
Virum & 5.5 & & 9.9 & & 15.2 \\
Værloese & 1.1 & & 15.3 & & 16.3 \\
Esrum I & 1.1 & & 12.0 & & 13.1 \\
Esrum II & 2.7 & & & 8.5 & 11.2 \\
\hline
\end{tabular}


On the consumption side of the balance, the gross heat consumption was determined by the energy class of the house, as stated in the energy performance (EP) certificate. The net heat consumption is defined as the maximum of heat per square meter per year that is allowed to pass through the building envelope set off against heat gained from solar radiation and internal loads such as people and appliances. Applied to the area of the house this loss must be added to the hot water consumption and adjusted for a possible indoor temperature other than $20^{\circ} \mathrm{C}$, see Table 4 . The supplement for higher indoor temperature is $7-10 \%$ per degree, lower for old houses and higher for new houses. The domestic hot water consumption was measured or stated to be $1 \mathrm{MWh}$ per person.

Table 4. The gross heat consumption as a total of the standard loss for the building adjusted for indoor temperature and hot water consumption.

\begin{tabular}{lccccc}
\hline Energy class & $\begin{array}{c}\text { Maximum heat } \\
\text { loss } \\
\left(\mathrm{kWh} / \mathrm{m}^{2}\right)\end{array}$ & $\begin{array}{c}\text { Building area } \\
\left(\mathrm{m}^{2}\right)\end{array}$ & $\begin{array}{c}\text { Net heat con- } \\
\text { sumption } \\
(\mathrm{MWh})\end{array}$ & $\begin{array}{c}\text { Gross heat } \\
\text { consumption } \\
(\mathrm{MWh})\end{array}$ \\
\hline Espergaerde & $\mathrm{D}$ & 134 & 226 & 30.3 & 43.5 \\
Ringsted & $\mathrm{B}$ & 76 & 170 & 12.8 & 17.7 \\
Hilleroed & $\mathrm{C}$ & 76 & 188 & 14.1 & 18.8 \\
Virum & $\mathrm{B}$ & 65 & 175 & 11.4 & 15.7 \\
Værloese & $\mathrm{B}$ & 65 & 126 & 8.2 & 14.0 \\
Esrum I & $\mathrm{A} 2$ & 65 & 132 & 8.6 & 13.3 \\
Esrum II & $\mathrm{A} 2$ & 65 & 120 & 7.8 & 11.7 \\
\hline
\end{tabular}

The resulting heat balance showed that in most cases the net heat production (excluded transformation loss) was lower than the expected gross heat consumption (included hot water consumption). This could be ascribed to low estimates of the amount of firewood consumed. However, in two cases the net heat production was higher than the expected heat consumption. In Esrum II this was presumably related to an inefficient heat pump, so that the yearly coefficient of performance was even lower that stated.

The energy balances also showed the share of heating resulting from wood burning as a total of the yearly energy production and as at total of the yearly consumption (see Figure 1). In these balances it was found that the share of heat production from wood burning was rather small. So far, an old house, like Espergaerde, with a masonry stove only had a wood-burning share of $20 \%$. Nevertheless, two new houses, Hilleroed and Esrum II reached a rather high share of $35 \%$ and $26 \%$ of the total energy consumption respectively. Still, the amount of wood used in Espergaerde was $2500 \mathrm{~kg}$ and by far the largest amount of wood used by any of the hosts. This showed that it was less demanding to cover the need for heating by use of a wood-burning stove in a modern house than in an elder house. By consuming a smaller amount of wood, a larger amount of fossil energy could be replaced and at larger amount of carbon circulation could be sustained. In that perspective it seemed promising to use firewood in new houses. 


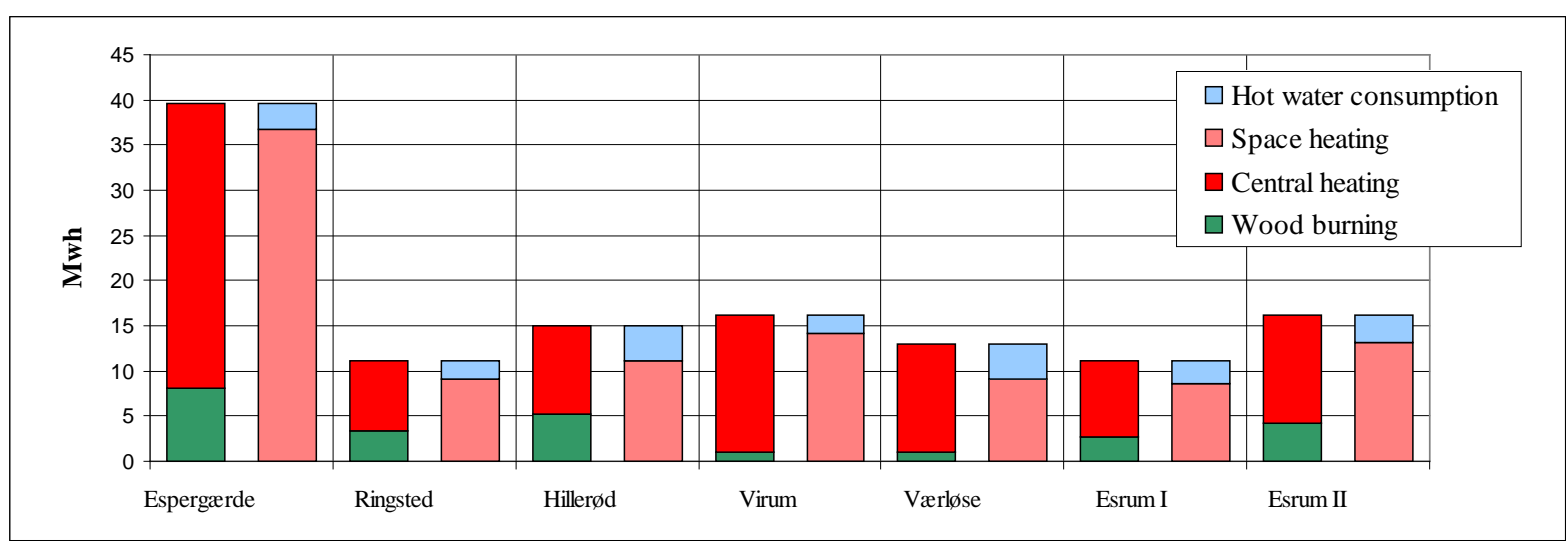

Figure 1. The heat balance based on the figures of net heat production, on one side divided into wood burning and central heating and on the other side into space heating and hot water production.

\subsection{Over heating}

An adjustment was made in the calculation of the gross energy to compensate for a possible indoor temperature other than $20^{\circ} \mathrm{C}$. In any case an average higher than $20^{\circ} \mathrm{C}$ was found, and as a consequence an adjustment of $3 \mathrm{MWh}$ per house on average was made (see above). This indicated that periods with high comfort temperature or even excessive temperatures might take place in houses heated by means of wood-burning stoves. To investigate the character of possible excessive temperatures, in the second period of measurement, the indoor temperature was logged every hour during the field measurements. In a few cases, temperature loggings were made in steps of two minutes. In short, the loggings showed that excessive temperatures, i.e. temperatures higher than $22^{\circ} \mathrm{C}$ often occurred. Usually the excessive temperatures happened once or twice a day during the heating season solely in houses with cast iron stoves. In contrast to houses with masonry stoves, the indoor the temperature in houses with cast-iron stoves often oscillated up and down once or twice a day, and sometimes more than 5 degrees in the heating season, see Figure 2.

The biggest adjustment for a high comfort temperature was made in the Espergaerde house. Here an average indoor temperature of $24.8^{\circ} \mathrm{C}$ was measured. However, in this house heated by masonry stove the temperature around the clock was rather constant.

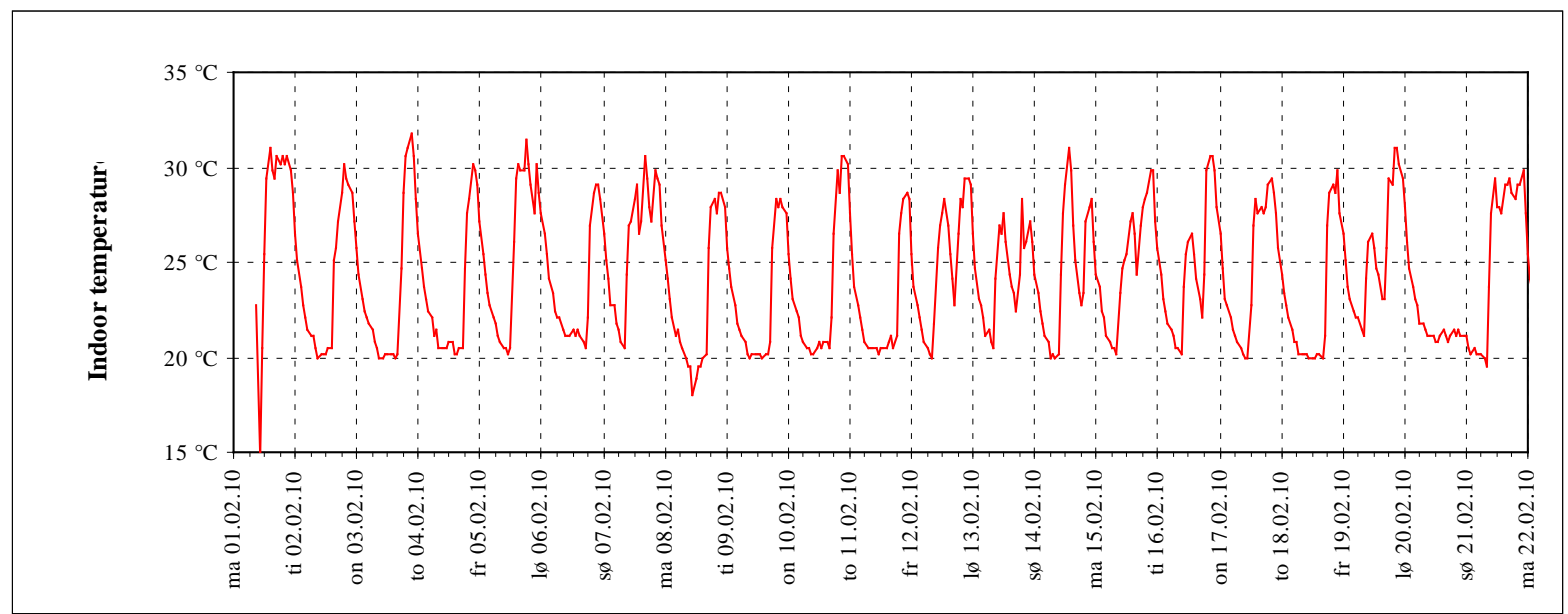

Figure 2. An example of temperature logging in an energy-efficient house carried out over 3 weeks in February 2010. The outdoor temperature in the period was just below $0^{\circ} \mathrm{C}$. (Energy Class A). 


\subsection{Energy performance discussion}

Comparing data from the measurements, the interviews and the questionnaires, it became evident that modern wood-burning stoves do function and to a large extent contribute to the heating, also in brand new houses. The advantage of masonry stoves is that they can distribute heat over a long period this way counteracting overheating. Surprisingly, the masonry stoves did not cover the biggest share of the heating, neither in the old house from 1977 (Espergaerde) nor in the new one from 2006 (Ringsted). In the first case the house had large energy consumption and in the second case, the house was equipped with floor heating. Combining stove heating and floor heating was usually less efficient.

\section{Indoor emission of particles}

Much research has been carried out to detect particle emission rates to the ambient environment. Through laboratory tests, and through measurement on the field is has been possible to set standards of particle emission from wood-burning stoves and to determine the environmental impact to neighbourhoods [6]. A topic neglected is that stoves emit particles to the indoor climate when being operated. Furthermore, among these particles are numerous of ultrafine particles, i.e. particles smaller than $0.1 \mu \mathrm{m}$. Particles of that scale are suspected of being even more harmful to health than particles smaller than $2.5 \mu \mathrm{m}$, which are the particles usually being measured. Therefore, the field study set out to look at how operation of a woodburning stove could cause emission of ultrafine particles and release of gases.

\subsection{Particle measurements}

Measurements were carried out in two periods, the heating seasons 2009/10 and 2009/10. The measurements started by monitoring the background concentration of particles indoors and outdoors. Then the wood-burning stove was lighted to operate for 1 or 2 hours. [7; 8]. The concentrations of ultrafine particles were monitored by means of two condensation particle counters; one was placed close to the stove, while the second one was used for sampling the outdoor concentration. The two instruments facilitated real-time measurement of particle number concentration. The detection ranges of the instruments ranged between 0.02 and about $1.0 \mu \mathrm{m}$. Carbon dioxide, temperature and relative humidity were recorded as well. Finally a passive, multiple tracer gas technique, the so-called PFT technique (PFT: PerFluorocarbon Tracer) was used to measure air-change rates [9]. The duration of the PFT measurements in each house was one week.

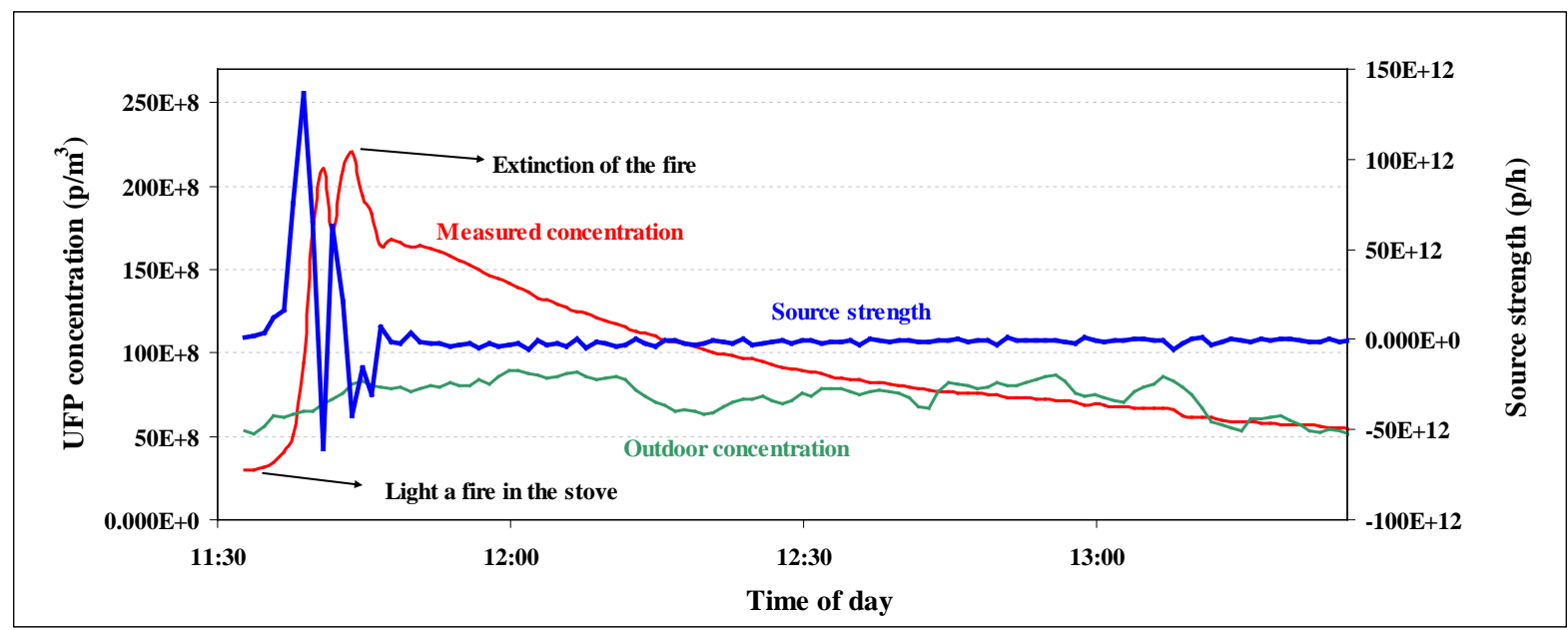

Figure 3. Typical picture of the development of ultrafine particles (UFP). In this case a large emission took place immediately after lighting a fire. 
Figure 3 shows that the concentration of ultrafine particles fluctuated for the first 15 minutes after the stove was lighted. A mass balance model, previously applied to analysis of gaseous contaminant concentration, was used. The calculated maximum source strengths and maximum concentration for al measurements of ultrafine particles is shown in Table 5. The concentration of measured ultrafine was fist published in [7; 8].

Table 5. Calculated maximum source strength $\left(\dot{M}_{\max }\right)$, and maximum concentration $\left(C_{\max }\right)$ for the ultrafine particles studied.

\begin{tabular}{lcccc}
\hline \multirow{2}{*}{$\begin{array}{l}\text { Measured and cal- } \\
\text { culated parameters }\end{array}$} & \multicolumn{2}{c}{$\begin{array}{c}\mathrm{C}_{\text {max }} \\
\left(\mathrm{p} / \mathrm{m}^{3}\right)\end{array}$} & \multicolumn{2}{c}{$\dot{M}_{\text {max }}$} \\
& Series 1 & Series 2 & Series 1 & Series 2 \\
\hline Espergaerde & $0.03 \cdot 10^{11}$ & $0.24 \cdot 10^{11}$ & - & $0.20 \cdot 10^{15}$ \\
Ringsted & - & $1.55 \cdot 10^{11}$ & - & $1.96 \cdot 10^{15}$ \\
Hilleroed & $0.05 \cdot 10^{11}$ & $0.11 \cdot 10^{11}$ & 0.00 & $9.19 \cdot 10^{7}$ \\
Virum & - & $0.99 \cdot 10^{11}$ & - & $1.60 \cdot 10^{15}$ \\
Værloese & $0.22 \cdot 10^{11}$ & $0.80 \cdot 10^{11}$ & $0.14 \cdot 10^{15}$ & $0.44 \cdot 10^{15}$ \\
Esrum I & $2.23 \cdot 10^{11}$ & $2.16 \cdot 10^{11}$ & $2.14 \cdot 10^{15}$ & $1.46 \cdot 10^{15}$ \\
Esrum II & $2.36 \cdot 10^{11}$ & - & $0.03 \cdot 10^{15}$ & - \\
\hline Espergaerde & $0.02-0.05 \cdot 10^{11}$ & $0.02-0.05 \cdot 10^{11}$ & 0.00 & - \\
\hline
\end{tabular}

\subsection{Particle emission discussion}

During the field study it became clear that in both series, with and without an expert lighting the fire, considerable emission of ultrafine particles to the indoor air might happen, in particular at lighting the fire and adding more wood. But other causes were identified as possibilities for particle pollution, like use of fabric gloves, touching the air valve and suddenly indoor draught. Peak concentration of particles was measured during lighting of a new stove installed in a brand new house (Esrum I and II). One possible explanation for the emission of particulate matter could be a negative indoor-outdoor pressure difference due to the mechanical ventilation system. Moreover, both of the houses mentioned were new, presumably rather airtight and the stoves had chimneys with a height of about 5 meters indoors.

The house in Hilleroed formed an exception in the series of measurements. In this house no elevated concentrations of ultrafine particles were measured except from a slight increase when the side lining of the furnace was dismounted in order to demonstrate the convection principle. The increase was recorded to be a maximum concentration of $0.11 \cdot 10^{11}$, i.e. double background concentration.

\section{Conclusion and recommendations}

It still seems promising to use a wood-burning stove in new houses. By using small amounts of wood up till one third of the heating demand could be met by this renewable energy resource. However, the field study confirmed that it is still a challenge for the manufactures of wood-burning stoves to meet the decreasing demand of wattage. Still more efficient buildings call for scaling down of the wattage, if overheating is to be prevented in future design. In this perspective masonry stoves were found to be the most adequate to new houses (e.g. the Ringsted house). The challenge to manufacturers of cast-iron stoves is to develop stoves with smaller combustion chambers and a better capability for distributing the heat. Use of heavy 
materials, like masonry stoves, phase change materials or connection to water reservoirs, if not to floor heating system it self may be a way of meeting the challenge. Scaling down the stoves means scaling down the size of the combustion chamber. This however makes it even more difficult to obtain a clean and efficient combustion process. Furthermore, possible pollution with particles and hazardous substances is more likely to happen. The tendency will be strengthened by the fact that highly developed wood-burning stoves are already today sensitive to airtight building envelopes and mechanical ventilation. In this field study it was found that modern stoves were actually extremely difficult to light and add more wood without causing particle emissions.

To conclude, there is a call for innovation of new smaller, more efficient and more particlesafe wood-burning stoves. Today already there is a need for guidance for salesmen and users of wood-burning stoves explaining not only the right size of the stove and the correct way of lighting it, but also the importance of an optimal interaction between stove and building.

\section{References}

[1] Danish Energy Agency, Energy Statistics, 2009.

[2] Danish Ministry of the Environment, Bekendtgørelse om regulering af luftforurening fra brændeovne m.v. (Executive order on regulation of air pollution from wood-burning etc), BEK nr 1432 af 11/12/2007.

[3] The European Parliament and of the Council of 16 December 2002 and of 19 May 2010 (recast) Directive 2002/91/EC and 2010/31/EU on the energy performance of buildings (EPBD).

[4] Nordic Labeling, Nordic Eco-labeling Closed Fireplaces, version 2.2, 2006.

[5] J. S. Andersen, Dimensionering af brændeovne (dimensioning of Wood-burning stoves), Danish Energy Agency (http://www2.mst.dk/WebApps/aspnetApps/_ex/Braendeovne/)

[6] M. Glasius, M. Ketzel, P. Wåhlin, R. Bossi, J. Stubkjær, O. Hertel, F. Palmgren, Characterization of particles from residential wood combustion and modelling of spatial variation in a low-strength emission area, Journal of Atmospheric Environment 42, 2008, pp 8686-8697, Elsevier.

[7] A. Afshari, O. J. Michael, N. C. Bergsøe, R. L. Carvalho, Impact of operating woodburning stoves on indoor air quality, Danish Building Research Institute, International Society of Indoor Air Quality and Climate, The $12^{\text {th }}$ Conference of Indoor Air 2011, 2010.

[8] R. L. Carvalho, Energy performance of wood-burning stoves and its impact on indoor air quality, Danish Building Research Institute, Master thesis in Sustainable Energy Systems, University of Aveiro, Portugal, 2010.

[9] N. C. Bergsøe, Passiv sporgasmetode til ventilationsundersøgelser (Passive tracer gas method for ventilation investigations). Danish Building Research Institute, SBi-rapport 227, 1992. 